www.jmscr.igmpublication.org

Impact Factor (SJIF): 6.379

Index Copernicus Value: 79.54

ISSN (e)-2347-176x ISSN (p) 2455-0450

crossrefDOI: https://dx.doi.org/10.18535/jmscr/v6i11.142

Journal Of Medical Science And Clinical Research

IGM Publication

An Official Publication of IGM Publication

\title{
Prospective Evaluation of Transconjuctival Muller's Muscle Resection for Minimal Congenital Ptosis with Relation to Phenylephrine test at a Tertiary Care Centre
}

\author{
Authors \\ Dr A.H. Madan ${ }^{1}$, Dr Swarana Gaikwad ${ }^{2}$, Dr Minal Vyawhare ${ }^{3 *}$, Dr Milind Changole ${ }^{4}$ \\ ${ }^{1}$ Professor and Head, Department of Ophthalmology, Government Medical College, Nagpur \\ Ph no: 9767763466, Email: dr.ashokmadan@gmail.com \\ ${ }^{2}$ Junior Resident, Department of Ophthalmology, Government Medical College, Nagpur \\ Ph no: 8855884399, Email: drswarna17@gmail.com \\ ${ }^{3}$ Assistant Professor, Department of Ophthalmology, Government Medical College, Nagpur \\ ${ }^{4}$ Assistant Professor, Department of Ophthalmology, Government Medical College, Nagpur \\ Email: dr.milind_21@yahoo.co.in, Ph no: 9555930395
}

*Corresponding Author

Dr Minal Vyawahare

Ph no: 9881563456, Email: drminalvyawahare@yahoo.com

\begin{abstract}
Aim: To evaluate results of transconjuncunctival muller's muscle resection for congenital ptosis with phenylepherine test.

Methods: This was a prospective study carried out at a tertiary care center in Central India. All patients with mild to moderate congenital ptosis were enrolled and any patient with previous surgery and corneal pathologies were excluded. MRD1, MRD2, amount of ptosis, Levator palpebrae superioris action and effect of phenylephrine test was noted. Graded transconjuctival muller's muscle resection was performed. Preoperative and post-operative parameters were compared. Data tabulated and analysis done.

Results: In the present study, total 21 patients were included with age ranging from 7 years to 26 years. In 12 cases only right eye was involved and in 9 cases left eye was affected. Female preponderance was observed. Average amount of ptosis was $2 \mathrm{~mm}$, average amount of phenylephrine improvement was $1.52 \mathrm{~mm}$. Muller muscle resection was carried out as $6 \mathrm{~mm}$ in 8 cases, $8 \mathrm{~mm}$ in 11 cases and $10 \mathrm{~mm}$ in 2 cases, each respectively. Levator palpebral superioris muscle action was in range from $8 \mathrm{~mm}$ to $15 \mathrm{~mm}$ with average of $10 \mathrm{~mm}$. None of the cases required resurgery.

Conclusion: The study concluded that muller's muscle transconjunctival surgery is very predictable surgery for mild to moderate ptosis with good levator function. Phenylephrine test helps to decide the plan and increases the predictability.
\end{abstract}

\section{Introduction}

Ptosis, an abbreviation for the term blepharoptosis, refers to vertical narrowing of the palpebral fissure secondary to drooping of the upper eyelid to a lower than normal position. Ptosis is considered congenital if present at birth or if it is diagnosed within the first year of life. Congenital ptosis is generally unilateral (70\%), 
but may be bilateral, and can be isolated or associated with disease of one or more of the extraocular muscles and/or other systemic conditions. ${ }^{(1,2)}$ More severe forms may involve hypoplasia of the levator palpebrae superioris muscle or tendon with a minimal or absent eyelid crease. $^{(3)}$

Children with this condition suffer from obstructed vision in their upper visual quadrants and frequently require surgery to elevate their eyelids. Ptosis can also be seen as a component of many congenital syndromes including blepharophimosis ptosis epicanthus inversus syndrome (BPES), congenital fibrosis of extraocular muscles, Duane retraction syndrome, Marcus Gunn jaw winking syndrome, and congenital Horner's syndrome. Congenital ptosis is a non-progressive condition, however, it is associated with the development of visual disturbances such as myopia, astigmatism, anisometropia, amblyopia, ocular torticollis, and strabismus. These sequelae of ptosis provide a compelling reason to pursue early surgical correction. $^{(4,5)}$

Correction of congenital ptosis is one of the most difficult challenges ophthalmologists face. Various methods are used for management of congenital ptosis including, frontalis sling, frontalis muscle flap, levator advancement, Whitnall sling, and Mullerectomy. Selection of one technique over another depends on the consideration of several factors including the the degree of ptosis in the patient ,surgeon experience, as well as the degree of levator muscle function. The graded muller's muscle resection is a well known procedure for management of mild to moderate congenital ptosis. In our study, Phenylephrine test was essential component of pre-operative work up as it helps to decide amount of muller's muscle resection. The goal of our study is to evaluate transconjunctival muller's muscle resection for mild to moderate ptosis with effect of phenyleperinine on amount of ptosis improvement. This study was conducted to prospectively compare different alogorithms that can more accurately demonstrate an advantage mullers muscle resection method.

\section{Aims}

1. To evaluate results of transconjunctival muller's muscle resection for congenital mild to moderate ptosis.

2. To evaluate the predictability of amount of correction of ptosis with phenylephrine test.

\section{Material and Methods}

This was a clinical, prospective, diagnostic study conducted in tertiary eye care center. Study was done over a period of 6 months. Written and informed consent was obtained from each patient's parents or guardian.

\section{Patient enrolment}

All patients with congenital ptosis were enrolled from ages 7 years to 23 years.

Exclusion criteria:

-Patients who have failed ptosis correction surgery.

-Patients who have undergone any other ocular surgery.

-Patients with any corneal pathology.

Presenting complaints, birth and medical history, Best Corrected Visual Acuity

(BCVA) by Snellens chart, applanation tonometry, slit lamp biomicroscopy, dilated fundus examination was carried out. MRD1, MRD2, amount of ptosis, LPS action and effect of phenylephrine test was noted. Amount of correction of ptosis by phenylephrine test was observed. Preoperative and post-operative parameters were compared and analyzed.

\section{Surgical steps}

All the cases were operated by a single surgeon. Under all aseptic precautions, under frontal block, traction lid suture taken and upper lid everted. Conjunctival incision taken. Muller's muscle identified and resected according to the amount of ptosis evaluated in each case after phenylepherine test. 


\section{Results}

A total of 21 patients were included in the study.

Demography:

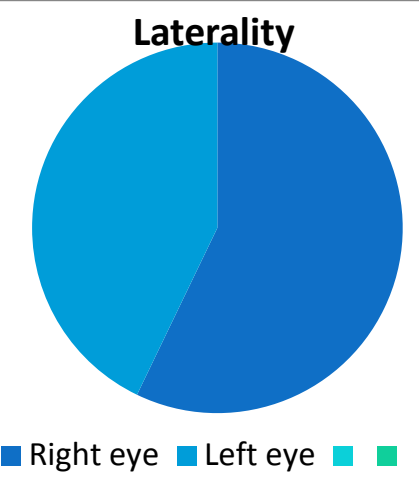

Diagram 1: Pie chart showing the affected eye

In total 21 cases, 12 cases only right eye was involved and in 9 cases left eye was involved.

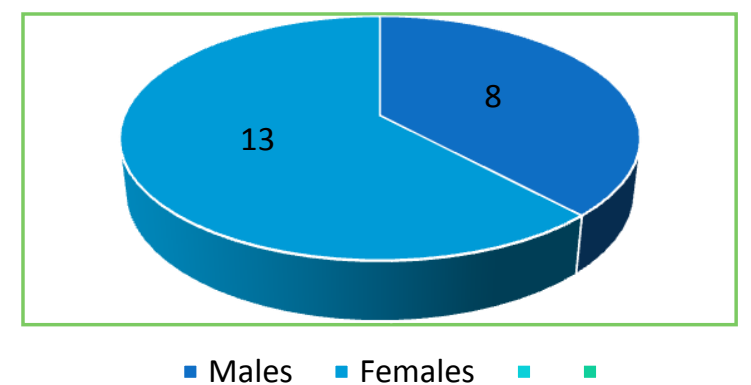

Diagram 2: Pie chart showing gender preponderance with females more than males A measurement of the distance between the corne al light reflex in the pupillary center, and of the margin of the upper eyelid when the eye is held in primary position is MRD1. The normal MRD 1 is $4 \mathrm{~mm}$ with a variation of $1 \mathrm{~mm}$. The Callahan and Beard classification of ptosis classifies mild ptosis as less than $2 \mathrm{~mm}$ and moderate ptosis as 3-4 $\mathrm{mm}$.

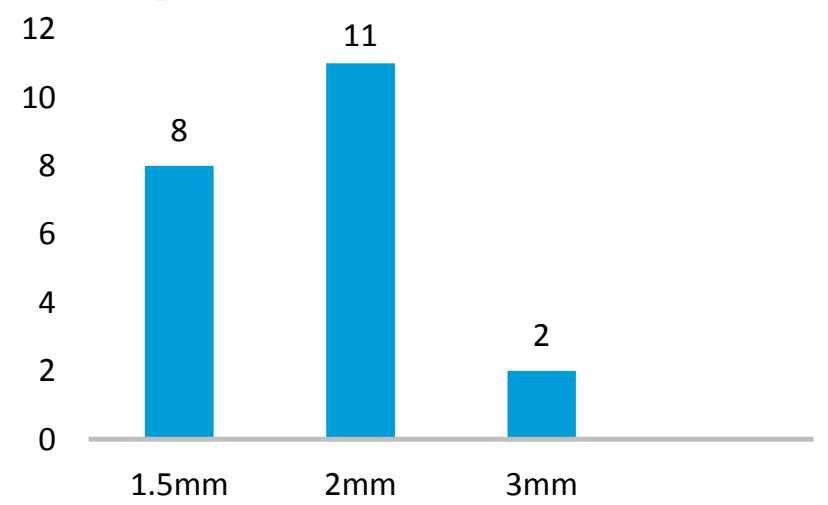

Diagram 3: Bar chart of the amount of ptosis present pre-operatively in 21 cases
In present study, 8 patients presented with $1.5 \mathrm{~mm}$ ptosis, 11 cases had $2 \mathrm{~mm}$ of ptosis and 2 patients had $3 \mathrm{~mm}$ of moderate ptosis.

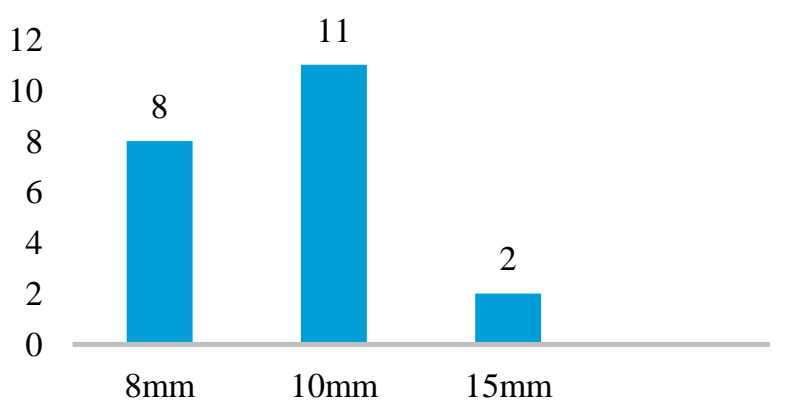

Diagram 4: Bar chart showing levator function in 21 cases

In present study levator palpebral superioris function was in range of $8-15 \mathrm{~mm}$ with 2 cases having $15 \mathrm{~mm}, 10 \mathrm{~mm}$ in 11 cases and $8 \mathrm{~mm}$ in 8 cases.

Phenylephrine test- $10 \%$ phenylephrine was instilled in the eyes of the patients with ptosis.

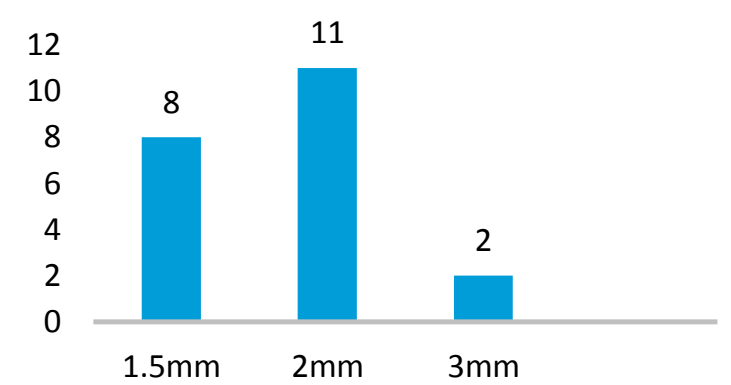

Diagram 5: Bar chart showing amount of ptosis improvement with phenylepherine drops.

In the present study, phenyleperine improvement was $1.5 \mathrm{~mm}$ in 8 cases, $2 \mathrm{~mm}$ in 11 cases, $3 \mathrm{~mm}$ in 2 cases.

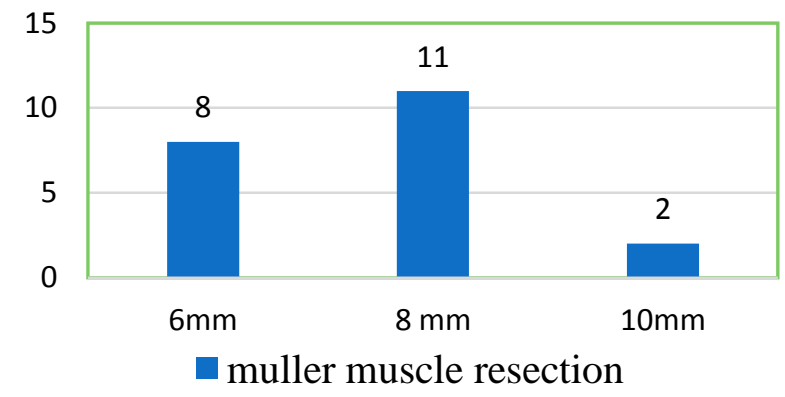

Diagram 6: Bar diagram showing amount of muller's muscle resection in 23 cases.

In present study, $6 \mathrm{~mm}$ of muller muscle was resected in 8 cases, $8 \mathrm{~mm}$ in 11 cases and $10 \mathrm{~mm}$ in 2 cases each. 


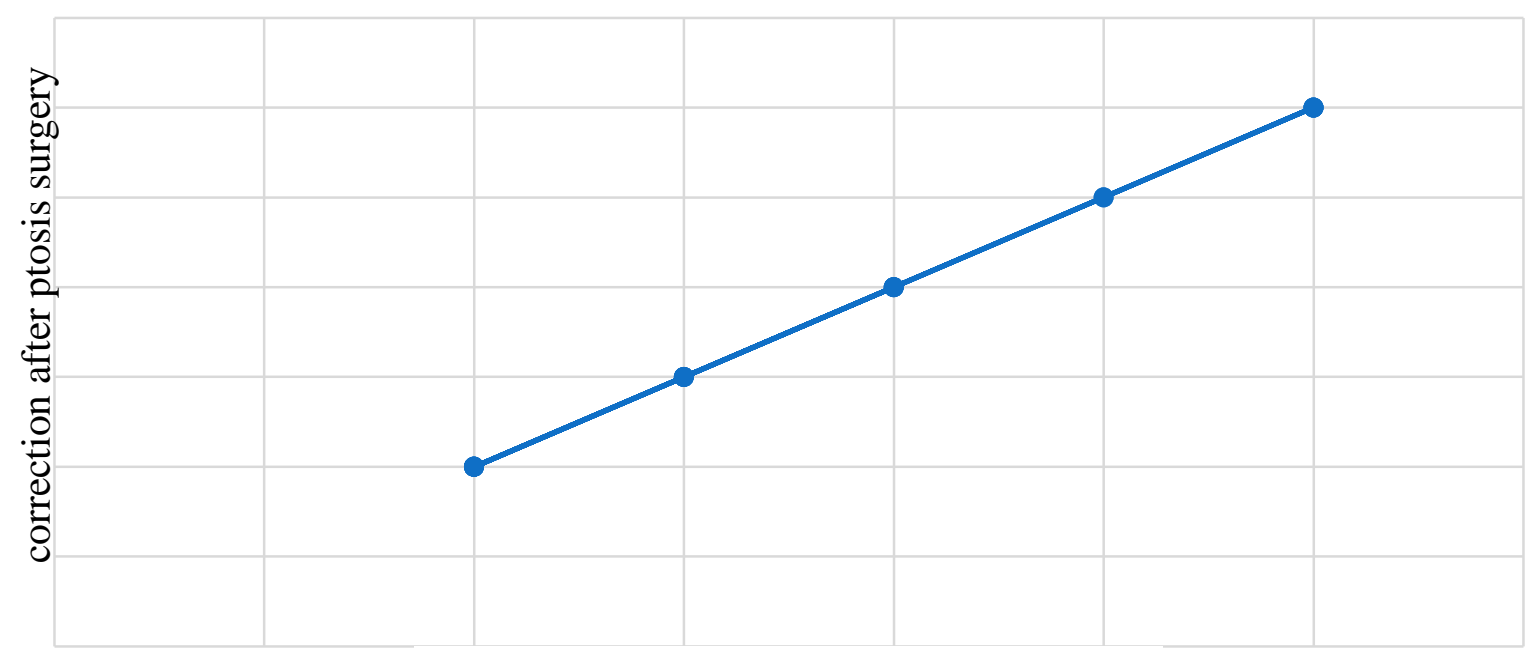

correction after instillation of phenylepherine drops

Diagram 7: Correlation of change in eyelid height after instillation of phenylephrine eyedrops and ptosis correction postoperatively.

Using Pearsons formula strong positive linear relationship is found between correction after phenylepherine test and after mild to moderate ptosis correction is seen with $(r=0.5)$

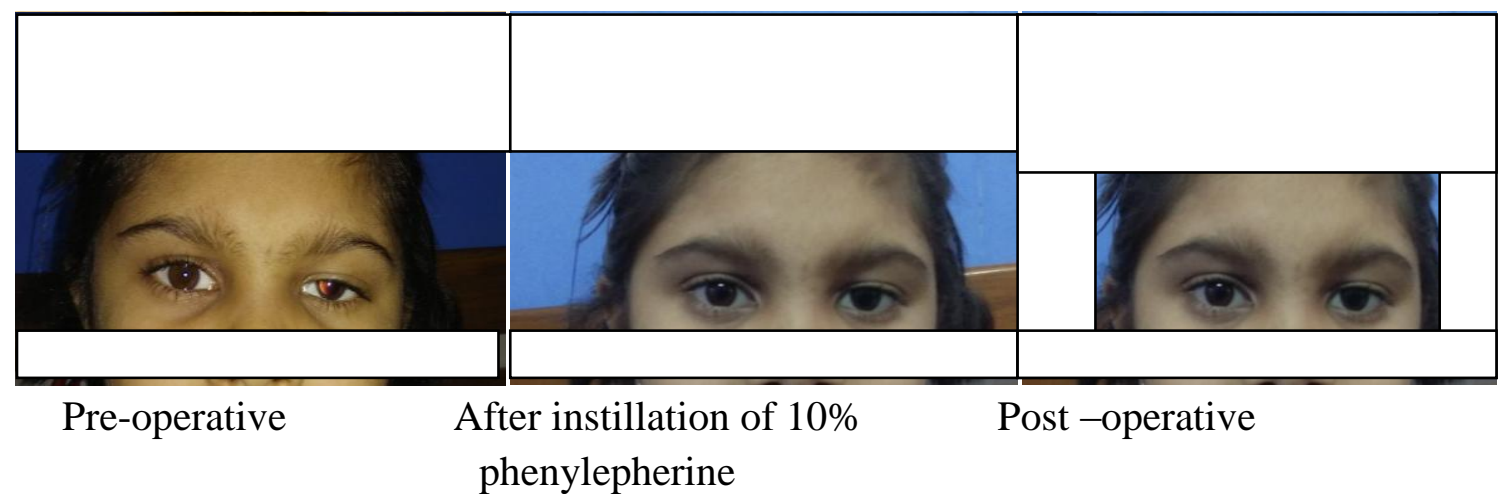

In this case, $2 \mathrm{~mm}$ of mild congenital ptosis was improved after instillation of $10 \%$ phenylepherine eyedrop and same improvement was seen postoperatively.

\section{Complications:}

Although complications invovled are less but includes under correction, overcorrection, subconjunctival haemorrhage, dry eye and lagophthalmos.

None of the cases in present study suffered from any of the complications.

\section{Discussion}

Muller's muscle-conjunctival resection (MMCR) resulted in improved eyelid position in patients with upper eyelid ptosis and good levator muscle function. The phenylepherine test estimated the ptosis correction achieved with MMCR. The eyelid crease did not change with MMCR, implying that the attachments of levator aponeurosis and skin orbicularis complex were not severed during surgery. Rates of overcorrection and undercorrection were very low. Various algorithms have been described for calculation of $\operatorname{MMCR}^{(7,8,9,10,11-13)}$. Although each method calls for a different extent of Muller's muscle resection for a similar desired degree of ptosis correction, most authors describe good results with eyelid symmetry of more than $80 \%$ and low rates of overcorrection. In present study we found similar results.

Putterman and $\mathrm{Fett}^{(9)}$ reported that an 8.25-mm resection should be performed if the ptotic eyelid 
is elevated to the desired level with preoperative $10 \%$ phenylephrine eyedrops, a 6.5 to $9.5 \mathrm{~mm}$ resection is performed if the ptotic eyelid is elevated higher or lower than the contralateral eyelid. Putterman and Fett ${ }^{(9)}$ summarized their 10year experience with MMCR and reported that $100 \%$ of those with congenital ptosis were within $1.5 \mathrm{~mm}$ of the level of the contralateral eyelid. Only 2 of 232 patients $(0.8 \%)$ required additional surgery. Blepharoplasty when performed with MMCR may reduce the anticipated postoperative eyelid elevation by $1 \mathrm{~mm} .^{(15)}$

Weinstein and Buerger ${ }^{(10)}$ used a standard 8-mm resection to correct 2-mm eyelid ptosis and added or subtracted $1 \mathrm{~mm}$ for every $0.25-\mathrm{mm}$ change in final eyelid position.

Dresner ${ }^{(11)}$ described a modified MMCR procedure for correction of blepharoptosis. In that study, 4-mm resection was performed to correct 1 $\mathrm{mm}$ of eyelid ptosis, $6-\mathrm{mm}$ resection to correct 1.5 $\mathrm{mm}$ of ptosis, and $8-\mathrm{mm}$ resection to correct $2 \mathrm{~mm}$ of ptosis. To correct $3 \mathrm{~mm}$ of eyelid ptosis, a 10$\mathrm{mm}$ resection was performed to avert placing the levator aponeurosis in the resection clamp. Dresner found a linear relationship between the extent of MMCR and postoperative eyelid correction $(\mathrm{r}=0.6)$. We used a similar algorithm and found a strong linear relationship between the extent of MMCR and ptosis correction, with $\mathrm{r}=0.5$. Dresner ${ }^{(11)}$ used a larger resection of 1 to 2 $\mathrm{mm}$ if the Phenylepherine test response was less than $2 \mathrm{~mm}$. It has been theorized that patients with poor response to Phenylepherine testing have fatty infiltration of the levator and Muller's muscles. $(10,13)$

Perry et $\mathrm{al}^{(12)}$ described a new algorithm for determining the extent of tissue excision in patients undergoing MMCR with or without tarsectomy to correct upper eyelid ptosis. The suggested formula was as follows: $9 \mathrm{~mm}$ of conjunctiva and Muller's muscle $\mathrm{x}$ mm of tarsus, where $\mathrm{x}$ represents the distance of under correction after Phenylepherine testing. Their algorithm was formulated on the basis that 9-mm resection of Muller's muscle yields similar eyelid elevation achieved with $10 \%$ phenylephrine eyedrops. Excision of a given amount of tarsus should result in a 1:1 ratio of eyelid elevation; therefore, any under correction seen after instillation of phenylephrine eye drops can be addressed by similar tarsal resection. Tarsal resection in the study by Perry and associates was limited to $2.5 \mathrm{~mm}$ to avert tarsal instability. All the new algorithm yielded predictable results, with eyelid symmetry achieved in $87 \%$ of 68 patients and $95 \%$ of patients satisfied with the surgical outcome. On analyzing results in present study, it seems that the phenylepherine test does accurately predict postoperative eyelid elevation. The average response to phenylephrine eyedrops in this study was $1.52 \mathrm{~mm}$, slightly lower than the 2 mm considered as an optimal response.

Muller's muscle-conjunctival resection is considered more reproducible and accurate than aponeurotic surgery in treating upper eyelid ptosis (3 mm) with good levator muscle function and when a positive response to topical phenylephrine has been documented. ${ }^{(8,9,11,14)}$ Excellent results can be expected in properly selected patients.

Given that previous studies in which slightly modified algorithms were used reported similar outcomes, it seems that muller muscle transconjunctival resection is an excellent and predictable surgical procedure for correction of eyelid ptosis with good levator muscle function. A prospective study comparing different algorithms can more accurately demonstrate an advantage of muller's muscle conjunctival resection.

\section{Conclusion}

Muller's muscle surgery is a very predictable surgery for mild to moderate congenital ptosis. Phenylephrine test helps to decide the plan and increases the post- operative predictability.

\section{Conflict of interest statement}

We declare that we have no conflict of interest. 


\section{References}

1. Smith B, McCord CD, Baylis H. Surgical treatment of blepharoptosis. Am J Ophthalmol. 1969:68:92-9. [PubMed]

2. Sakol PJ, Mannor G, Massaro BM. Congenital and acquired blepharoptosis.

Curr Opin Ophthalmol. 1999:10:3359. [PubMed]

3. Guercio JR, Martyn LJ. Congenital malformations of the eye and orbit. Otolaryngol Clin North Am. 2007:40:113-40. [PubMed]

4. Langford JD, Linberg JV, Blaylock WK, Chao GM. Axial myopia in congenital ptosis: An animal model. Ophthal Plast Reconstr Surg. 1998:14:261-5. [PubMed]

5. Kao SC, Tsai CC, Lee SM, Liu JH. Astigmatic change following congenital ptosis surgery. Zhonghua Yi XueZaZhi (Taipei) 1998:61:689-93. [PubMed]

6. Langford JD,Linberg JV, Blaylock WK, Chao GM. Axial myopia in congenital ptosis: An animal model. Ophthal Plast Reconstr Surg.1998:14:261-5[PubMed]

7. Putterman AM, Urist MJ. Mu“ller's muscle-conjunctival resection. Arch Ophthalmol. 1975:93(8):619-623.

8. Guyuron B, Davies B. Experience with the modified Putterman procedure. Plast Reconstr Surg. 1988:82(5):775-780

9. Putterman AM, Fett DR. Mu“1ler's muscle in the treatment of upper eyelid ptosis: a ten-year study. Ophthalmic Surg. 1986:17(6):354-360.

10. Weinstein GS, Buerger GF Jr. Modifications of the Mu"ller's muscleconjunctival resection operation for blepharoptosis. Am J Ophthalmol. 1982:93(5):647-651

11. Dresner SC. Further modifications of the Muller's muscle-conjunctival resection procedure for blepharoptosis. Ophthal Plast Reconstr Surg. 1991:7(2):114-122.

12. Perry JD, Kadakia A, Foster JA. A new algorithm for ptosis repair using conjunctival Mu“llerectomy with or without tarsectomy. Ophthal Plast Reconstr Surg. 2002:18(6):426-429.

13. Baldwin HC, Bhagey J, Khooshabeh R. Open sky Muller muscleconjunctival resection in phenylephrine test-negative blepharoptosis patients. Ophthal Plast Reconstr Surg. 2005:21(4):276-280.

14. Morax S, Ben Ayed H, Pereira-Nunes T, Hamedani M. Advantages of a double approach to upper blepharoplasty associated with eyelid malpositions [in French]. J Fr Ophtalmol. 2003:26(9):993997.

15. Brown MS, Putterman AM. The effect of upper blepharoplasty on eyelid position when performed concomitantly with Muller muscle-conjunctival resection. Ophthal Plast Reconstr Surg. 2000:16(2):94-100. 